\title{
Els postulats de la filologia romànica internacional sobre l'origen, la identitat i el nom de la llengua catalana (1806-1906)
}

\section{The postulates of the international romance philology about the origin, identity and name of the Catalan language (1806-1906)}

\author{
Adrià Martí-BAdia \\ adria.marti@uv.es \\ Universitat de València
}

\begin{abstract}
Resum: Aquest treball analitza els postulats dels romanistes no catalanòfons sobre l'origen, la identitat i el nom de la llengua catalana entre 1806 i 1906. Al segle xix es situa l'inici de la filologia romànica, i cada vegada més erudits cataloguen $\mathrm{i}$ estudien les diferents llengües romàniques. Progressivament, en aquest període els romanistes prenen en consideració la llengua catalana, i realitzen afirmacions sobre el seu origen -compartit amb la llengua occitana $\mathrm{o}$ independent des de l'inici-, la seua identitat -subordinada a l'occità o autònoma com la resta de llengües romàniques- $\mathrm{i}$ el nom amb què cal referir-s'hi.
\end{abstract}

Paraules clau: Llengua catalana, Filologia romànica, Segle xix, Origen, identitat i nom de la llengua catalana

Abstract: This paper analyses the postulates of the non-Catalan-speaking Romanists about the origin, the identity and the name of the Catalan language between 1806 and 1906. Romance philology emerges in the 19th century and scholars started to categorize and study the different romance languages. Progressively, during this period, Romanists take into consideration the Catalan language and make statements about its origin -shared with the Occitan language or independent from the beginning-, its identity -subordinated to Occitan or autonomous as the other romance languages- and the name with which the language should be mentioned.

Keywords: Catalan language, Romance philology, 19th century, Origin, identity and name of the Catalan language 
Adrià Martí-Badia. Els postulats de la filologia romànica internacional sobre l'origen, la identitat i el nom de la llengua catalana (1806-1906)

\section{Introducció}

$\mathrm{Al}$ segle XIX es situa l'inici de la filologia romànica, que inaugura el filòleg alemany Friedrich Christian Diez amb la publicació del primer volum de la Grammatik der romanischen Sprachen el 1836, pedra inicial d'aquest vast i complex edifici. S'hi feia esment del català, encara que les informacions eren escasses i insegures. L'any 1870 Diez publica la tercera edició de la seua gramàtica, en la qual millora molt el text referit a la llengua catalana. A partir d'aleshores el català, bé com a llengua, bé com a dialecte, no deixa d'ésser pres en consideració pels romanistes (Badia i Margarit 1989: 7-8). ${ }^{1}$

$\mathrm{El}$ «problema» del reconeixement del català com a llengua independent és evident quan la naixent ciència lingüística comença a elaborar un llistat de les llengües derivades del llatí (Calaforra 1998: 27). La primitiva lingüística romànica no comptava, però, amb una definició satisfactòria de conceptes com «llengua», «dialecte» $\mathrm{i}$ «parla», i per a distingir-los es valia d'arguments extralingüístics com l'antiguitat dels documents escrits, els usos literaris, l'extensió geogràfica, el nombre de parlants, el prestigi i la situació política, entre d'altres; tots ells arguments arbitraris des del punt de vista lingüístic. Així, sense un estat al darrere, era difícil que el català fora considerat com una llengua independent.

Així doncs, el nostre objectiu és analitzar el posicionament dels romanistes internacionals sobre l'origen, la identitat i el nom de la llengua catalana entre els anys 1806 i 1906. La primera data es correspon amb la publicació de Mithridates oder allgemeine Sprachenkunde (1806-1817) pels filòlegs alemanys Johann Christoph Adelung i Johann Severin Vater, mentre que la segona s'escau amb la celebració del Primer Congrés Internacional de la Llengua Catalana a Barcelona.

\section{El català com a parla romànica subordinada}

Els primers filòlegs d'aquest període que fan referència al català són els alemanys Johann Christoph Adelung i Johann Severin Vater en la seua obra de lingüística general titulada Mithridates oder allgemeine Sprachenkunde (1806-1817), concretament en el segon volum, en el qual esmenten el català indistintament com a llengua de Catalunya i com a parla del castellà (1809: 544-545).

També és el cas de l'erudit occità François Raynouard, que entre 1816 i 1821 publica el recull de poesia trobadoresca Choix des poésies originales des Trobadours. En aquesta obra manifesta la tesi d'una llengua diferent del llatí vulgar intermediària entre el llatí i les llengües romàniques, que anomena «llengua romana» i que identifica amb el provençal, de la qual derivarien totes les llengües romàniques. Una tesi que el català Antoni de Bastero ja l'havia exposada un segle abans. Bastero, «que és considerat el primer gran romanista, veritable predecessor de Raynouard i dels romanistes del segle XIX» (Solà 1985: 466),

1 Badia i Margarit (1989: 8) afirma que Diez «a la segona edició de la Gramàtica (1856) millorà molt el text referit a la llengua catalana», però en realitat aquestes millores es produïren -com hem indicat adés- en la tercera edició. De fet, en la segona edició (1856) Diez es manté en la teoria llemosinista, tal i com ho demostra Müller (1983: 401).

SCRIPTA, Revista internacional de literatura i cultura medieval i moderna, núm. 13 / juny 2019 / pp. 60 - 80 ISSN: 2340-4841 · doi:10.7203/SCRIPTA.13.15436 
Adrià Martí-Badia. Els postulats de la filologia romànica internacional sobre l'origen, la identitat i el nom de la llengua catalana (1806-1906)

va publicar La crusca provenzale (1724) i va deixar inèdita una incompleta Història de la llengua catalana. Resumidament, la tesi de Bastero -que posteriorment repetirà Raynouard amb més aparat científicconsisteix en els següents arguments: en primer lloc, el català i el provençal són la mateixa llengua; en segon lloc, aquesta llengua antigament s'anomenava «llengua romana»; en tercer lloc, aquesta llengua es va originar del llatí i, al seu torn, va originar les altres llengües romàniques (Solà 1985: 466).

Pel que fa al català, Raynouard (1816-1821) no l'analitza, però en el quart volum -titulat Grammaire comparée des langues de l'Europe latine dans leurs rapports avec la langue des troubadours - afirma que el català és la llengua més acostada a l'esmentada «langue romane» (1821: XxxviII). ${ }^{2}$ També afirma que existeixen gramàtiques i diccionaris que fixen el català, subratlla la seua regularitat «interna» i conclou la seua especificitat entre els idiomes veïns (1821: xxxix), com assenyala Calaforra (1998: 28).Anys més tard, concretament el 1836, Raynouard publica Influence de la langue romane rustique sur les langues de l'Europe latine, obra dedicada a la influència de la «llengua romana» entre les llengües romàniques. En aquest treball esmenta el català entre les sis «llengües» derivades de la «llengua romana», al costat del provençal, el castellà, el portugués, l'italià i el francés (Raynouard 1836: 1). D'altra banda, entre 1836 i 1844 publica els sis volums del Lexique roman ou dictionnaire de la langue des troubadours, comparée avec les autres langues de l'Europe latine, ${ }^{3}$ en la qual compara «les rapports souvent identiques, des six langues néolatines», les quals són «la langue des troubadours, la langue catalane, la langue espagnole, la langue portugaise, la langue italienne, la langue française» (Raynouard 1836: I). Així, Raynouard equipara el català amb el castellà, el portugués, l’italià i el francés i, a més, empra el sintagma inequívoc «langue catalane» per a referir-se al català. Ara bé, al llarg d'aquest estudi Raynouard no considera que el català és una llengua plenament independent, encara que sí es mostra partidari de reconéixer-li una certa autonomia.

En definitiva, el provençal seria -segons Raynouard- la «lingua romana» de què parlen els textos medievals, la qual va dominar a França entre els segles vi i Ix i de la qual derivarien el francés, l'italià i el castellà (Vàrvaro 1988: 30-35).

Entre els romanistes que no consideren el català com a llengua independent $\mathrm{i}$ amb identitat pròpia també cal incloure l'alemany August Wilhelm von Schlegel, que l'any 1818 publica Observations sur la langue et la littérature provençales, obra en què von Schlegel rebat la tesi exposada per Raynouard (18161821) i defensa que totes les llengües romàniques són llengües mixtes -resultat de la influència germànica sobre el llatí- que s'originaren de manera semblant però autònomament (Vàrvaro 1988: 32-33). A pesar d'això, Raynouard insistirà en la seua posició en les obres següents (1821, 1836-

\footnotetext{
2 La traducció d'aquest fragment és de Calaforra (1998: 27).

3 Alguns investigadors citen els anys 1838-1844 com a data de publicació del Lexique roman de Raynouard, com és el cas de Solà (1985: 467) i Bayà i Pascual (1992: 27, 44), entre d'altres. Aquesta errada es deu, ben probablement, al fet que el primer volum d'aquesta obra fou publicat l'any 1838. Ara bé, el segon volum fou publicat l'any 1836, dos anys abans que el primer. D'altra banda, el segon volum fou l'únic dels sis que Raynouard va veure publicat abans de morir; els altres cinc (els volums I, III, IV, V i VI) es van publicar pòstumament.
}

SCRIPTA, Revista internacional de literatura i cultura medieval i moderna, núm. 13 / juny 2019 / pp. 60 - 80 ISSN: 2340-4841 · doi:10.7203/SCRIPTA.13.15436 
Adrià Martí-Badia. Els postulats de la filologia romànica internacional sobre l'origen, la identitat i el nom de la llengua catalana (1806-1906)

1844). Pel que fa al català, Schlegel l'identifica amb el provençal i afirma que és una llengua viva que es parla a Catalunya, al regne de València, a les Illes Balears i al sud de França (1818: 2). ${ }^{4}$

En aquest grup també podem incloure l'alemany Lorenz Diefenbach, que l'any 1831 publica Über die jet̨igen romanischen Schriftsprachen, el primer estudi comparatiu de les llengües romàniques (Müller 1983: 401), entre les quals hi descriu i hi compara el castellà, el portugués, el retoromànic, el francés, l'italià i el dacoromanés, però no el provençal ni el català. D’aquesta omissió, doncs, deduïm que Diefenbach no considerava el català entre les llengües romàniques.

El mateix cas és el de l'anglés George Cornewall Lewis, que l'any 1835 va publicar An essay on the origin and formation of the Romance languages, obra sobre l'origen i la formació de les llengües romàniques en què critica la tesi de Raynouard, afirma que a Catalunya, València i les Illes Balears es parla un dialecte «que s'assembla més a la llengua d'oc que a l'espanyol o castellà escrit» (1835: 47) i, per a més informació, remet a una nota a peu de pàgina («sobre la relació del valencià i el català amb el provençal vegeu Raynouard») on cita el primer volum del Choix des poésies originales des Trobadours (1816) i el quart, titulat Grammaire comparée des langues de l'Europe latine dans leurs rapports avec la langue des troubadours (1821).

Més tard, entre 1836 i 1844, l'alemany Friedrich C. Diez publica la Grammatik der romanischen Sprachen, en la qual rebat definitivament la tesi de Raynouard i estableix que les llengües romàniques tenen el seu origen en el llatí parlat pels romans i no en el llatí clàssic dels escriptors, els quals coexistien (Solà 1985: 467). A l’inici del manual afirma:

Sis llengües romàniques atreuen la nostra atenció, a causa de la seva originalitat gramatical o de la seva importància literària: dues a l'est, l'italià i valac; dues al sud-oest, l'espanyol i el portuguès; dues al nord-oest, el provençal i el francès (1836: 3). ${ }^{5}$

A més, considera el català un dels «tres dialectes [romànics] fonamentals» de la península Ibèrica, al costat del gallec i del castellà (1836: 71). ${ }^{6}$ De fet, en el primer volum, Diez (1836) compara les llengües literàries, però exclou els dialectes sense justificar-ho; i agrupa els dialectes en l'àmbit geogràfic de la llengua literària corresponent. Aquest criteri no era aplicable al provençal -perquè

4 Von Schlegel identifica en més ocasions el català amb el provençal, però no fa una definició tan clara com l'esmentada adés. Per exemple, més endavant von Schlegel (1818: 40) diu: «Il y a quelque difficulté à bien désigner la langue des Troubadours. Les noms de langue provençale, limousine, catalane, qu'on lui a donnés, sont trop étroits, parce qu'ils n'embrassent qu'une des provinces où elle étoit indigène, et qu'elle avoit un territoire beaucoup plus vaste». També quan afirma que «Le provençal, le limousin, le catalan, formoient un seul dialecte central dans l'Europe latine» (Schlegel 1818: 51), o quan sosté que «Ainsi, le Dante paroît avoir complétement ignoré l'existence de la langue castillane, puisqu'il étend sur toute l'Espagne le domaine de la langue d'oc, c'est-à-dire du provençal ou du catalan» (Schlegel 1818: 106).

5 La traducció d'aquest fragment és de Calaforra (1998: 31).

6 Ibid., Calaforra, p. 30.

SCRIPTA, Revista internacional de literatura i cultura medieval i moderna, núm. 13 / juny 2019 / pp. 60 - 80 
Adrià Martí-Badia. Els postulats de la filologia romànica internacional sobre l'origen, la identitat i el nom de la llengua catalana (1806-1906)

l’identificava com a llengua literària morta- però sí al català, raó per la qual la seua agrupació amb el provençal contradiu els seus mateixos principis i Diez es veu obligat a concedir-li certa autonomia sense atribuir-li un lloc a banda (Vàrvaro 1988: 52). En canvi, en el segon volum, Diez (1838) examina directament els sistemes individuals dels diferents parlars romànics, relaxa un poc la rígida classificació del primer volum i al tractament del provençal antic el segueixen breus apèndixs sobre dialectes moderns i sobre el català antic (Vàrvaro 1988: 60).

Anys després, entre 1856 i 1860, publica la segona edició de la Grammatik, en la qual replanteja els criteris de classificació de les llengües, afegint el pes de la literatura i les característiques gramaticals, però el català continua amb les mateixes consideracions que a la primera edició: «L'espanyol no s'estén per tot el regne com a llengua popular; el nord-oest d'aquest pertany a la branca portuguesa, i l'est pertany a la provençal» (1856: 97; Calaforra 1998: 31). De fet, Müller (1983: 401) veu en l'actitud de Diez la influència de les idees del ja esmentat Lorenz Diefenbach. Ara bé, Diez basa -en part- la seua posició provençalista en la poesia catalana menys occitanitzada, com la d'Ausiàs March o Jaume Roig (Seifert 1936: 195; Calaforra 1998: 31). A més, Diez fa alguna referència al valencià, que inclou dins del català, com quan afirma que

en la presentació de les relacions fonètiques es pot limitar a la forma catalana, ja que el valencià és idèntic [i les formes catalanes i valencianes] només es distingeixen-segons Mayans- per una poca major suavitat (1856: 113).

Tot i això, en la segona edició Diez manté la consideració de dialecte per al català en alguns exemples, ${ }^{7}$ junt amb alguna referència al català antic com a llengua. ${ }^{8}$ Com indiquen Bayà i Pascual (1992: 38), aquest darrer exemple potser es deu al fet que Diez fa referència a una obra literària antiga, criteri d'importància literària que el romanista alemany emprava sovint per a distingir entre llengua i dialecte; però, en definitiva, són exemples que demostren que Diez vacil lava a l'hora de determinar la identitat del català. De fet, el tractament del català en la seua obra en alguns punts mostra indefinició i en altres, contradicció (Calaforra 1998: 31). Ara bé, com veurem en l'apartat següent, Diez rectifica la seua posició en les edicions posteriors de la Grammatik.

Un altre exemple dels romanistes que no consideraven el català com a llengua romànica independent és l'alemany August Fuchs, que en la seua obra Über die sogenannten unregelmässigen Zeitwörter in der romanischen Sprachen afirma que el català és un «dialecte espanyol» (1840: 72), com també ho són el «dialecte gallec» i el «dialecte lleonés», ${ }^{9}$ un nom amb el qual Fuchs -segons Calaforra (1998: 32)-

\footnotetext{
7 Per exemple, quan diu en el segon volum: «Der catalanische Artikel lautet schon in den ersten Denkmälern dieser Mundart» (Diez 1858: 40).

8 Ibid.: «In der älteren catalanischen Sprache, z. B. bei Ramon Muntaner, lautet das Personalpron. yo, tu, ell, ella (...)» (Diez 1858: 96).

9 Fuchs analitza primer «Die Galizische Mundart» (1840: 50-58), a continuació el «Leonische Mundart» (1840: 58-69) i finalment «Die Katalanische Mundart» (1840: 69-99).
}

SCRIPTA, Revista internacional de literatura i cultura medieval i moderna, núm. 13 / juny 2019 / pp. 60 - 80 ISSN: 2340-4841 · doi:10.7203/SCRIPTA.13.15436 
Adrià Martí-Badia. Els postulats de la filologia romànica internacional sobre l'origen, la identitat i el nom de la llengua catalana (1806-1906)

els considera «dialectes d'Espanya», ja que cap dels tres apareix en la seua relació de «llengües». Concretament, pel que fa al català, assegura que aquest ha sofert la influència de la llengua del sud de França -en referència a l'occità (1840: 70). Més tard, l'any 1849 Fuchs publica l'obra Die romanischen Sprachen in ibrem Verbältnisse zum Lateinischen, en la qual estudia les llengües romàniques en relació amb el llatí i només fa referència a les «parles catalanes», que comprenen l'àrea del Rosselló, Catalunya, Illes Balears i Pitiüses, el regne de València i la ciutat sarda de l'Alguer (1849: 70).

També és el cas de J. F. Schnakenburg, doctor en filosofia, membre de la Société de l'Histoire de France i professor a l'Escola Militar Universal de Berlin, centre que aleshores tenia l'estatus d'universitat. L'any 1840 va publicar Tableau synoptique et comparatif des idiomes populaires ou patois de la France, en què afirma que

el dialecte català s'estén per la Mediterrània, a través del regne de València, a les illes de Mallorca, Menorca i Eivissa i es parla a França al Rosselló. Es diferencia del castellà i per les característiques principals dels dialectes del sud de França, potser siga més exacte relacionarlo amb la llengua roman que amb l'espanyol. Els mateixos catalans i valencians veuen aquesta afinitat, tant que sempre l'anomenen llengua llemosina (1840: 25-26).

Un altre cas semblant és el del romanista anglés Arthur Bruce-Whyte, que en la seua obra titulada Histoire des langues romanes et de leur littérature (1841), considera que el català era un dialecte del provençal i manifesta que «les pretensions dels catalans [de tindre una llengua independent] ens semblen totalment desproveïdes de proves i fins i tot de probabilitat» (1841: 388). Unes pàgines més endavant afirma que encara no s'ha descobert cap producció catalana anterior a finals del segle XIII que es puga comparar amb la llengua dels trobadors (1841: 393). I, finalment, sosté que el provençal va prevaldre per sobre del català fins a l'aparició d'Ausiàs March (1841: 406).

També podem incloure en aquest grup al comparatista alemany August Schleicher que, en la seua obra Die sprachen Europas in systematischer Uebersicht (1850), considera el català un dialecte de «la llengua escrita provençal» (1850: 151), ${ }^{10}$ una parenta del provençal entre les parles principals d'Espanya (1850: 166). I assevera que només hi ha cinc llengües romàniques dignes d'estudi: l'italià (1850: 163-166), el portugués (1850: 169-172), el provençal (1850: 172-179), el castellà (1850: 166169) i el francés (1850: 179-185). ${ }^{11}$

10 Schleicher (1850: 173) torna a referir-se al català en uns termes semblants quan diu: «In Italien gehörte der piemontesische Dialekt mehr dem Provenzalischen als dem Italienischen, und in Spanien reichte das catalonische Provenzalisch am mittelländischen Meere entlang bis über Alicante hinaus; auch auf den Balearischen Inseln setzte es sich fest».

11 Schleicher, després d'haver analitzat l'italià (1850: 163-166), el castellà (1850: 166-169), el portugués (1850: 169172), el provençal (1850: 172-179) i el francés (1850: 179-185), afirma: «Die bisher charakterisirten fünf Sprachen sind zugleich die einzigen, die in ihrer systematischen Ausbildung, in ihrer festen Abrundung und literarischen Fähigkeit, den sprachlichen Gedanken des romanischen Stammes zu klarer und übersichtlicher Erscheinung bringen. Sie sind unter den Ablegern, in denen der verdorrte lateinische Sprachbaum neue Wurzel geschlagen hat, die einzigen, die, jeder für sich, zu vollkommenem Wuchs gediehen sind, die einzigen, deren physiologisches Studium einem höheren wissenschaftlichen Interesse zu genügen scheint» (1850: 185).

SCRIPTA, Revista internacional de literatura i cultura medieval i moderna, núm. 13 / juny 2019 / pp. 60 - 80 ISSN: 2340-4841 · doi:10.7203/SCRIPTA.13.15436 
Adrià Martí-Badia. Els postulats de la filologia romànica internacional sobre l'origen, la identitat i el nom de la llengua catalana (1806-1906)

El romanista francés Alfred Morel-Fatio és un altre dels que consideren que el català és un dialecte de l'occità. Ho afirma quan s'encarrega de redactar l'apartat dedicat al català en la primera edició del Grundriß de Gustav Gröber (1888: 669-688). En primer lloc, Morel-Fatio exposa quins són els territoris on actualment es parla la llengua catalana: en la part oriental dels Pirineus, en una franja prou ampla de la costa est de la península Ibèrica, a les Illes Balears, en la ciutat de l'Alguer, a l'illa de Cuba i a la república Argentina; a França inclou els antics comtats del Rosselló, Vallespir, Conflent, Cerdanya i Capcir i té uns 200.000 habitants; i a Espanya abasta les quatre províncies de l'antic Principat de Catalunya (Girona, Barcelona, Tarragona i Lleida), tres de l'antic regne de València (Castelló de la Plana, València i Alacant) i la província de les Illes Balears (o antic regne de Mallorca), amb un total de població de 4.500.000 habitants, enfront dels 14.000.000 que parlen castellà a les altres províncies espanyoles i dels 2.000.000 que parlen gallec (1888: 669). En segon lloc, unes pàgines endavant, Morel-Fatio explica quina és la subagrupació romànica del català: «el català pertany a la família gal loromànica i no a la hispànica (castellanoportuguesa); no és tampoc un membre intermedi entre ambdues, sinó mera variant del provençal» (1888: 673). És a dir, d'una banda, Morel-Fatio assevera nítidament que el català és una mera variant del provençal i que, per tant, està subordinat a aquesta; d'altra banda, i probablement sense pretendre-ho, MorelFatio enceta la polèmica de la subagrupació romànica del català, a la qual posteriorment s'afegiran nombrosos romanistes, com és el cas de Jean-Joseph Saroihandy, Heinrich Morf, Antoni Griera, Ramón Menéndez Pidal, Amado Alonso, Walter von Watburg, Meyer-Lübke, Pere Fouché, ${ }^{12}$ Jakob Jud, Marie Hagedorn, Alwin Kuhn, Vicente García de Diego, Gerard Rohlfs, Joseph Piel, Germà Colón, Francesc de B. Moll, Antoni M. Badia i Margarit, Joan Coromines i Manuel Sanchis Guarner, entre d'altres. ${ }^{13}$

També és interessant la consideració que fa Morel-Fatio respecte a la consciència lingüística dels valencians, mallorquins i menorquins, dels quals deia que aquests estaven convençuts que no parlaven català, sinó valencià, mallorquí i menorquí -respectivament-, com a conseqüència del particularisme que es va desenvolupar amb el pas del temps en els nous territoris conquerits per a la Corona catalanoaragonesa (regne de València i regne de Mallorques) (1888: 671). Unes afirmacions que no s'ajusten a la realitat del País Valencià, tal i com hem documentat en el treball Martí-Badia (2018), de la mateixa manera que Massot i Muntaner (2018) ho ha il lustrat pel que fa a l'illa de Mallorca. Resulta difícil d'entendre l'explicació de Morel-Fatio respecte a la consciència lingüística dels valencians, mallorquins i menorquins, sobretot si tenim en compte les circumstàncies prèvies a la seua redacció del capítol «Das Catalanische» que es va publicar dins el Grundriß de Gröber (1888). Ens referim al viatge d'un mes que Morel-Fatio va fer l'abril de 1881 a Mallorca, mentre era professor a l'École Supérieure des Lettres d'Alger (Algèria), amb l'objectiu d'estudiar la història dels dialectes de les províncies del nord-est d'Espanya i la preparació d'un recull d'antics textos catalans,

12 Filòleg rossellonés més conegut amb el nom Pierre Fouché.

13 Vegeu la panoràmica que exposen Baldinger (1972: 125-160), Sanchis Guarner (1980: 18-21), Badia i Margarit (1981: 6-12) i Moll (2006: 37-45) sobre la problemàtica de la subagrupació romànica del català.

SCRIPTA, Revista internacional de literatura i cultura medieval i moderna, núm. 13 / juny 2019 / pp. 60 - 80 ISSN: 2340-4841 · doi:10.7203/SCRIPTA.13.15436 
Adrià Martí-Badia. Els postulats de la filologia romànica internacional sobre l'origen, la identitat i el nom de la llengua catalana (1806-1906)

resultat del qual fou l'esmentat treball de 1888 (Massot i Muntaner 2018: 131). Una estada en què va conéixer, recomanat pel seu mestre Paul Meyer, a Marià Aguiló i a altres escriptors i erudits mallorquins com Tomàs Forteza (Massot i Muntaner 2018: 131-134).

Una de les opinions més influents de l'època fou la del romanista suís Whilhelm Meyer-Lübke ${ }^{14}$ que entre 1890 i 1901 publica la primera edició de la Grammatike der romanischen Sprachen, l'objectiu de la qual era ampliar i millorar l'obra homònima de Friedrich C. Diez, i així li ho van reconéixer filòlegs importants, tant de la seua època -Gustav Gröber- com posteriors -Carlo Tagliavini- (Calaforra: 1998: 24). L'elecció de llengües a estudiar que fa Meyer-Lübke (1890-1901) no és sobre el principi geogràfic-cultural i s'estén als idiomes romànics més marginals i descuidats sense prejudicis de natura extralingüística (Vàrvaro 1988: 108-109). Pel que fa al català, Meyer-Lübke no considera el català com una de les llengües romàniques -com el romanés, el retoromànic, l’italià, el provençal, el francés, el castellà i el portugués- i afirma que «el català és un provençal portat a Espanya el s. VIII, que avançà progressivament cap al sud amb la lluita dels reis aragonesos contra els àrabs» (1890: 14). ${ }^{15}$

Aquest llistat de llengües romàniques establert per Meyer-Lübke l'amplia en l'Einfübrung in das Studium der romanischen Sprachwissenschaft (1901), en el qual afegeix llengües com el sard i el dàlmata, però no el català, que situa com a dialecte provençal al mateix nivell que el gascó, el llenguadocià, el provençal, el valdés, l'alvernés i el llemosí. ${ }^{16}$ De fet, Meyer-Lübke afirma que «el català és un dialecte del provençal que va avançar amb el retrocés dels àrabs, que es parla en la costa mediterrània amb València, Barcelona i inclou les illes Balears i Pitiüses» (1901: 23-24). Segons Kuhn (1937: 780), l'Einfübrung de Meyer-Lübke

no és cap introducció per a principiants, sinó més aviat una sistematització de la lingüística romànica, un compendi i una radioscòpia crítica i cientificopedagògica de tots els problemes que, en el treball sobre la Romània sencera per a la seva gramàtica romànica, se li havien donat com a difícilment solubles. ${ }^{17}$

El català també és considerat un dialecte del provençal pel romanista italià Antonio Restòri, professor de literatura romànica a la Università di Pavia, quan l'any 1891 publica el manual de Letteratura provenz̧ale. A l'inici del segon capítol, dedicat al nom i extensió de la llengua provençal, afirma que la llengua provençal en el seu sentit més ampli, no només abasta tot el migdia de França, sinó també Catalunya i l'antic comtat de València [sic] fins als Pirineus, incloses les Illes Balears (1891: 17). I, a continuació, descriu i delimita les «quatre grans varietats» d'aquesta llengua, entre

14 Per a la seua vida i obra vegeu Kuhn (1937: 778-784) i Calaforra (1998: 19-76).

15 La traducció és de Calaforra (1998: 86).

16 En la llista de dialectes que conformen el «provenzalisch», Meyer-Lübke (1901: 21) esmenta els següents: «Gaskognisch», «Katalanisch», «Languedokisch», «Provenzalisch», «Waldensisch», «Auvergnisch» $\mathrm{i}$ «Limousinisch».

17 La traducció d'aquest fragment és de Calaforra (1998: 22).

SCRIPTA, Revista internacional de literatura i cultura medieval i moderna, núm. 13 / juny 2019 / pp. 60 - 80 ISSN: 2340-4841 · doi:10.7203/SCRIPTA.13.15436 
Adrià Martí-Badia. Els postulats de la filologia romànica internacional sobre l'origen, la identitat i el nom de la llengua catalana (1806-1906)

les quals trobem «el franco-provençal al nord-est, el provençal al centre, el gascó al sud-oest, i més enllà dels Pirineus, el català» (1891: 19).

En uns termes molt semblants s'expressa un any després l'italià Vincenzo Crescini, catedràtic d'història comparada de llengües i literatures romàniques a la Università di Padova des de 1883, que va centrar els seus estudis en la literatura provençal. L'any 1892 publica el Manualetto provenzale per uso degli alunni delle facoltà di lettere, en la introducció del qual afirma que el català és un dialecte de la llengua provençal -al mateix nivell que el gascó- que s'estén pel comtat del Rosselló, Catalunya, València, Balears i la colònia de l'Alguer (1892: XIV). Una afirmació que manté en la segona edició -esmenada i augmentada- de 1905 (1905: 2).

També és el cas del geògraf i lexicògraf Gottardo Garòllo, que entre 1892 i 1895 dirigeix la publicació dels dos volums de la Piccola Enciclopedia Hoepli. En l'entrada corresponent als catalans afirma que aquests són «els habitants de Catalunya, València, i Balears, que parlen un dialecte provençal (català), que també és llengua escrita i té literatura pròpia» (1892: 663).

Altrament, també hi van haver vacil lacions dins l'obra dels mateixos romanistes, com en el cas d'Egidio Gorra, filòleg italià i professor d'història comparada de les literatures neollatines a la Università di Torino. L’any 1894, Gorra publica l'obra Lingüe neolatine dins la col lecció «Manuali Hoepli». ${ }^{18}$ En el quart capítol, titulat «les llengües neollatines» (1894: 75), Gorra considera que el català és una llengua com el romanés, el ladí o rètic, l'italià, el francés, el provençal, el francoprovençal, l'espanyol i el portugués (1894: 93); un inventari que, segons Calaforra (1998: 33), Gorra pren de la tercera edició de la Grammatik de Meyer-Lübke i del Grundriß de Gröber. Ara bé, unes pàgines més endavant Gorra afirma que el català ha d'unir-se al provençal, ja que és una de les seues varietats dialectals, que fou transportada a Espanya en el segle viII i que es parla a França en la major part del Departament dels Pirineus (1894: 99). Una formulació teòrica que, segons Calaforra (1998: 32), no és un invent de Meyer-Lübke perquè ja apareix abans dels seus treballs, però que fou ell qui la va consagrar.

Ja al segle xx, cal esmentar el cas del romanista austríac Adolf Zauner, deixeble de Meyer-Lübke que l'any 1900 va publicar Romanische Sprachwissenschaft, en el qual també considera el català un dialecte del provençal amb les paraules següents: «el català, que a l'est del mateix país [Espanya] era generalitzat (que, per cert, sovint es considera un llenguatge romànic especial a causa del seu ús literari a l'Edat Mitjana), pertany al Provençal» (1900: 13). Una afirmació que manté en la segona edició de l'obra, amb una xicoteta variació que no canvia el significat (1905: 22). Zauner, per tant, es mantenia en la posició tradicional.

18 Calaforra (1998: 32-33) i Müller (1983: 408) -d'on Calaforra extreu la informació- citen l'any 1898 com a data de publicació de l'obra de Gorra, però aquesta obra es va publicar el 1894. De fet, Calaforra (1998:33) cita el fragment de Gorra (1984: 99) i indica la pàgina 93, però aquest es troba en la 99. 
Adrià Martí-Badia. Els postulats de la filologia romànica internacional sobre l'origen, la identitat i el nom de la llengua catalana (1806-1906)

En el grup occitanista també cal esmentar el romanista alemany Oskar Schultz-Gora, catedràtic a la universitat de Königsberg des de 1904, que en la primera edició de la seua obra Altprovenzalisches Elementarbuch afirmava que la frontera sud del provençal s'estenia més enllà dels Pirineus, on el català -que ocupava una àmplia franja de la costa est espanyola (capital Barcelona) i a les Illes Balears- només es pot considerar una varietat del mateix», és a dir, del provençal (1906: 8).

\section{El català com a llengua romànica independent}

El primer romanista que reconeix el català com a llengua independent és l'alemany Friedrich C. Diez. Ho fa l'any 1827 amb la publicació d'una recensió a l'obra Floresta de rimas antiguas castellanas de l'hispanista alemany Böhl de Faber, en un passatge de la qual Diez separa clarament el territori lingüístic català del territori lingüístic occità (Seifert 1936: 196). Ara bé, com hem vist adés, Diez adopta la posició tradicional segons la qual el català és un dels dialectes de l'occità amb la publicació de les primeres dues edicions de la Grammatik der romanischen Sprachen (1836-1844 i 1856-1860, respectivament).

Més endavant, en la tercera edició -publicada l'any 1870- Diez torna a la posició no-occitanista quan modifica la part dedicada al català que havia escrit en les primeres dues edicions, $i$ ara afirma que el català no és una parla del provençal, sinó que és més aviat un idioma independent:

\footnotetext{
La llengua catalana -perquè a[i]xí es podria anomenar segons la província veïna que s'estèn per l'est d'Espanya, les Illes i la província francesa del Rosselló- es relaciona respecte del provençal no pas com un dialecte; és més aviat un idioma autònom emparentat amb aquell; i, al país on es parla, tot i que molts dels seus poetes escriguessin en provençal, mai no s'ha reconegut aquesta llengua com a llengua literària (1870: 112). ${ }^{19}$
}

Aquesta consideració pel que fa al català es mantindrà en les dues edicions següents de l'obra -la quarta, publicada entre 1876 i 1877 i la cinquena i última, de 1882. Malauradament, però, Diez no va canviar el capítol introductori, en què el català rebia un tracte que es contradeia amb la posició de les pàgines interiors de l'obra (Müller 1983: 401-402).

És a partir d'aquests estudis de Diez que en l'últim quart del segle xix diferents romanistes reconeixen la independència del català respecte a la resta de llengües romàniques. Un d'ells és el filòleg alemany Gustav Körting, que entre 1884 i 1888 publica l'Ensyklopädie und Methodologie der romanischen Philologie, al tercer volum de la qual presenta el següent llistat d'idiomes romànics, agrupats per afinitats: «a) grup sud-oriental (portuguès, espanyol, català); ${ }^{20}$ b) grup nord-occidental (provençal, francès); c)

19 La traducció d'aquest fragment és de Calaforra (1998: 85).

20 Com adverteix Calaforra (1998: 28), ací Körting s’equivoca i, on diu «grup sud-oriental», voldria dir «grup sudoccidental».

SCRIPTA, Revista internacional de literatura i cultura medieval $i$ moderna, núm. 13 / juny 2019 / pp. 60 - 80 
Adrià Martí-Badia. Els postulats de la filologia romànica internacional sobre l'origen, la identitat i el nom de la llengua catalana (1806-1906)

grup central (retoromànic i italià); d) grup oriental (romanès)» (1886: 64). ${ }^{21} \mathrm{I}$, més endavant, defineix el català com a llengua independent amb les següents paraules: «En qualsevol cas, però, des del principi de l'època literària el català es troba enfront del provençal com a llengua germana molt emparentada amb aquest, però autònoma d'ell, i no s'hi subordina com a dialecte» (1886: 480). ${ }^{22}$ Ara bé, Körting canvia d'opinió l'any 1896 quan publica el Handbuch der romanischen Philologie, en el qual assevera que «al provençal pertany també el català, ja que aquest no és res més que un provençal transportat a Espanya (Catalunya, València, Balears i Pitiüses) que hi ha arribat a tenir un desenvolupament literari» (1896: 303). ${ }^{23}$ Segons el filòleg Bodo Müller (1983: 404), en aquest retrocés en la percepció del català per part de Körting hi ha una clara reminiscència de la Grammatik der romanischen Sprachen de Wilhelm MeyerLübke, el primer volum de la qual va aparéixer el 1890, com hem vist adés.

També és el cas del romanista alemany Fritz Neumann, que l'any 1886 publica Die romanische Philologie, ein Grundriß, en la qual afirma que el català abans era considerat una «parla» del castellà o del provençal, però que ara es considera una llengua independent amb les paraules següents: «Emperò, hom reconeix avui per al català, generalment, la posició de llengua romànica autònoma» (1886: 64). ${ }^{24}$

El més contundent entre els no-occitanistes és l'historiador espanyol Marcelino Menéndez Pelayo, deixeble de Manuel Milà i Fontanals, que el 1889 escriu en el pròleg a l'edició completa de les poesies de Joaquim Rubió i Ors (Rafanell 2006: 123):

\begin{abstract}
basta abrir un tomo de modernas poesias catalanas y otro escrito en provenzal moderno, para convencerse de que, en cuanto á su espíritu, no tienen entre sí más semejanza que la que pueden tener un poeta francés y otro castellano, un italiano y otro portugués. Las dos lenguas, por otro lado, han ido olvidándose tanto de su parentesco primitivo que exigen de una parte y otra esfuerzos de aprendizaje no menores que los que requiere cualquier otra lengua romance (1889: XVII).
\end{abstract}

En aquest grup també cal incloure el romanista alemany Gustav Gröber, que entre 1888 i 1901 publica el Grundriß der romanischen Philologie, en el qual titula les diferents seccions amb noms com «la llengua romanesa», «les parles retoromàniques», «la llengua italiana», «les llengües francesa $i$ provençal i les seues parles», «el català», «la llengua espanyola» i «la llengua portuguesa». Per tant, Gröber cataloga la llengua catalana com a varietat pròpia, però deixa oberta la classificació en la jerarquia dels idiomes, ja que no la presenta ni com a dialecte ni com a llengua (Müller 1983: 405406). Així, la posició de Gröber seria favorable a una certa consideració d'autonomia per al català, però d'una indefinició oberta a debat (Calaforra 1998: 29).

21 La traducció d'aquest fragment és de Calaforra (1998: 28).

22 Ibid.

23 Ibid.

24 Calaforra (1998: 29).

SCRIPTA, Revista internacional de literatura i cultura medieval i moderna, núm. 13 / juny 2019 / pp. 60 - 80 ISSN: 2340-4841 · doi:10.7203/SCRIPTA.13.15436 
Adrià Martí-Badia. Els postulats de la filologia romànica internacional sobre l'origen, la identitat i el nom de la llengua catalana (1806-1906)

Un altre dels romanistes que afirmen la independència del català és l'escriptor alemany i doctor en filosofia Otto Denk, que l'any 1893 publica Einfübrung in die Geschichte der altkatalanischen Litteratur von deren Anfängen bis zum 18. Jahrbundert. A l'inici de l'obra, Denk escriu una breu introducció a la història de la llengua catalana i descriu breument l'expansió del català a l'Edat Mitjana (Wittlin 1992: 121-122). Pel que fa a la primera qüestió, Denk explica que la marca hispànica és el bressol de la llengua catalana, que va sorgir del llatí vulgar i que en els documents del segle x ja figura sota el nom de lingua vulgaris, rustica o communis, el català és una branca del llatí vulgar, com ho és l'occità i l'espanyol, encara que és més propera al castellà que al francés del sud; i acaba afirmant: «com va dir el mestre Diez, no és un dialecte sinó una llengua en si mateixa» (1893: XXVII). A més, Denk afirma que el català arriba al País Valencià i a les Illes Balears amb la conquesta del rei Jaume I (1893: xxxiv).

L’any 1902 és el torn del filòleg espanyol Ramón Menéndez Pidal, que publica un article al diari madrileny El Imparcial intitulat «El catalán y los catalanistas. Cataluña bilingüe». En aquest article Menéndez Pidal reconeix la independència del català, el cataloga com a llengua i defensa l'espanyolitat d'aquesta. Malgrat el que sembla indicar el títol i el subtítol de l'article, «les tesis exposades per Menéndez Pidal se sustenten en la historia (...), descansen sobre la seva consubstancial espanyolitat de base» (Rafanell 2006: 198-199). Així, segons Menéndez Pidal,

\begin{abstract}
En el siglo XII un provenzal, Rimbaldo de Vaqueiras, en una de sus poesías escritas en diversos idiomas, quiso incluir una muestra de lenguaje peninsular. Pues bien, no crea el Catecismo citado que escogió como muestra el catalán (que al fin era el que tenía más cerca) sino el castellano, por la sencilla razón de que, mientras los poetas catalanes no sabían aun escribir sino en una lengua extraña, en provenzal, ya el castellano ostentaba una robusta y singularísima poesía épica, altamente nacional, mucho antes que Berceo y Alfonso x lo elevasen a una primitiva perfección literaria. Por el contrario, hasta muy a finales del siglo XIII no empezaron los catalanes a querer dignificar su lengua para la poesía, y cuando lograron una lengua poética, la llamaron lemosina, para indicar su esfuerzo de imitación extranjera y su desdén por el pla catalá. ¡Por esto, sin duda, el Catecismo enseña que el catalán estaba ya en esplendor cuando el castellano aún no daba señales de vida!! ${ }^{25}$ (...) Yo, aun con temor de disentir de la fórmula fonética pastoral, tengo por más acertada la fórmula que dan los romanistas: al catalán le falta el sonido de la $u$ francesa, que es la que caracteriza el grup lingüístico hablado en Francia, Provenza y Norte de Italia.

Aunque los exaltados crean que el catalán no tiene más relación histórica con el español que la que le impone la presión gubernamental de Madrid, es lo cierto que vivió desde su origen en intimo comercio con el castellano ó el aragonés. No ya á partir de la fecha en que Fernando de Antequera y la dinastía de Castilla dieron á la corona de Aragón su más alto grado de esplendor; antes del admirable compromiso de Caspe, tan maldecido de los exaltados, el catalán se castellanizaba ó aragonesizaba profundamente, no admitiendo tales ó cuales palabras sueltas, sino alterando su estructura, su declinación, su sistema de particulas, bajo el influjo del idioma que desde sus comienzos manifestó el espíritu expansivo que le había de extender por España y América. Aunque el catalán resistiese más tiempo á estas innovaciones, el hablado las admitia francamente, y buen
\end{abstract}

25 Com explica Rafanell (2006: 199-200), aquesta referència de Menéndez Pidal a l'Església es deu al fet que el 6 de gener de 1900, Josep Morgades i Gili -aleshores bisbe de Barcelona- va publicar una carta pastoral sobre la llengua de la predicació i el catecisme, en la qual reivindicava el català i afirmava que aquesta llengua era més semblant a l'italià i al francés que al castellà.

SCRIPTA, Revista internacional de literatura i cultura medieval i moderna, núm. 13 / juny 2019 / pp. 60 - 80 ISSN: 2340-4841 · doi:10.7203/SCRIPTA.13.15436 
Adrià Martí-Badia. Els postulats de la filologia romànica internacional sobre l'origen, la identitat i el nom de la llengua catalana (1806-1906)

\begin{abstract}
testimonio de ello es la colonia catalana que en 1354 pobló la ciudad de Alguer en Cerdeña; esta población continuó aislada hablando catalán, y hoy después de seis siglos, los filólogos estudian su lengua, notando en ella los muchos aragonesismos y castellanismos que los catalanes del siglo XIV usaban; lo cual prueba que el catalán antiguo no era una lengua tan soberana é independiente como los catalanistas gustan de creer.

Lo que ya no pueden desconocer es el hecho de que la castellanización del catalán fué inmensa á partir del último tercio del siglo xv. Entonces la poesía catalana, que había empezado á florecer treinta ó cuarenta años antes, decaía notablemente, no sólo en Barcelona, donde nunca había brillado mucho, sino en Valencia, que era la capital intelectual de la zona catalano-valenciana. Los poetas de Levante, cansados de la disciplina erudita de una escuela amanerada, se acogieron gustosos á escribir en castellano, atraídos á un centro superior de cultura y de vida nacional fresca y exuberante. (...) Y no sólo tocaba la castellanización á la clase elevada, á los literatos y eruditos; sino que el pueblo, que jamás había comprendido la fría escuela lemosina, al sentir ahora el inflamado aliento de una literatura nacional, despertó de su largo sueño y concibió una poesía popular rica y variada, como hasta entonces no habia tenido. Aprendió de memoria los romances castellanos, y los repitió sin cesar, como modelo admirable; de tal suerte que luego, al imitar su metro y su estilo en lengua catalana, queriendo ennoblecer la propia poesía la salpicaba de voces castellanas (1902: 1ab).
\end{abstract}

D’una banda, aquest article traspua «el dolor per la pèrdua de les colònies darreres que Castella havia creat el segle XVI» (Trueta 1988: 6) i, de l'altra,

hi ha la prevenció enfront d'un moviment organitzat que prenia l'argument lingüístic com a motiu focal. Si algú començava a predicar que el català no era ben bé una varietat «ibèrica», consegüentment podia passar que alguns catalans acabessin per sostenir que el seu país tampoc no n'era ben bé, d'«ibèric» (Rafanell 2006: 200-201).

I és que «l'esmena a la totalitat de Menéndez Pidal no venia pas guiada per cap instint, per cap aprensió imaginària. Al contrari, la seva correcció la guiava un temor ben fonamental i ben fonamentat» (Rafanell 2006: 201). ${ }^{26}$

L'any 1904 es publica la segona edició del Grundriß de Gröber, i en aquesta ocasió de l'apartat dedicat al català se n’encarrega el romanista francés Jean-Joseph Saroihandy (1904: 841-877), que el revisa i l'actualitza, considerant el català com a llengua independent:

Les estretes relacions polítiques que durant molt de temps han vinculat el Rosselló i la Cerdanya francesa amb Catalunya expliquen, d'altra banda, per què es parla la mateixa llengua a banda i banda dels Pirineus orientals (1904: 846). ${ }^{27}$

Més tard, el 20 de març de 1906, Saroihandy envia una carta a Antoni M. Alcover, en la qual li argumenta la seua posició, ben probablement impel lit perquè el canonge mallorquí li hauria

26 L’article de Menéndez Pidal va provocar una discussió amb diferents erudits catalanoparlants com Artur Masriera i Colomer, Pere Muntanyola i Carner, Jaume Massó i Torrents i Antoni M. Alcover. Per a aquesta polèmica vegeu Rafanell (2006: 201-206).

27 La traducció d'aquest fragment és de Calaforra (1998: 86).

SCRIPTA, Revista internacional de literatura i cultura medieval i moderna, núm. 13 / juny 2019 / pp. 60 - 80 
Adrià Martí-Badia. Els postulats de la filologia romànica internacional sobre l'origen, la identitat i el nom de la llengua catalana (1806-1906)

retret que afirmara que el català era una llengua independent de l'occità (Rafanell 2006: 321-322). Saroỉhandy li diu que ambdós estan d'acord, si és que Alcover creia que el català va nàixer als Pirineus i no que fou importat de França; i que per a ell és secundari saber si el català i l'occità conformen la mateixa branca, ja que allò important és que ambdues llengües venen del mateix tronc. ${ }^{28} \mathrm{Com}$ afirma Rafanell (2006: 322), «el que realment importava a Saroïhandy, com a bon neogramàtic, era l'arbre genealògic. La resta se li presentava com un bosc immens, impossible d'abastar».

Finalment, els dies 2 i 3 de març de 1905 es manifesta el romanista alemany Bernhard Schädel. El professor de la Universität de Halle an der Saale, que un any abans havia conegut a mossén Alcover a Mallorca, va publicar dos articles sobre la història de la llengua catalana al periòdic alemany Kölnische Zeitung, aleshores un dels diaris més importants d'Alemanya. El català Joaquim Casas i Carbó els va traduir al català i el primer d'aquests es va publicar el 8 d'abril del mateix 1905 al setmanari El Poble Català (Rafanell 2006: 314). En l'article, Schädel comença indicant on es parla la llengua catalana:

El català avui día no solament se parla en l'Espanya oriental, a Barcelona y Valencia, a les Balears y Alguer en la illa de Sardenya, sinó que també pertanyen an aquest domini lingüistic la part fronterissa de Fransa pel cantó de Perpinyà, es a dir, el territori de l’antic comtat del Rosselló (1905: 2e).

A continuació, resumeix l'origen de la llengua i afirma:

No ha de maravellar, doncs, a ningú que la aproximació llingüística y cultural vingués dantse la mà ab la política. En la vella Marca Hispànica y en la regió limítrofe de la Septimania, la Gallia gòthica, se forma aviat el català com llengua popular comuna a tots dos paíssos (1905: 2f).

I, finalment, el romanista alemany desaprova a aquells que encara neguen el caràcter de llengua independent del català:

\footnotetext{
La gran analogía que aquesta última llengua tenía ab la propia del Mitjía de Fransa y el gust ab que'ls catalans l'aplicaren fins al segle xv, han estat la causa de que encara avui dins Espanya i a Alemanya hi ha qui nega al català'l caràcter de llengua independent. Aquest judici tindría algun fonament si's tinguessin solament en compte les produccions líriques mitjevals que no van poder resistir l'influencia avassalladora de les formes provensals que havíen penetrat en els Pirineus (1905: 3a).
}

A més, l'encapçalament de l'article remet a una nota a peu de pàgina del traductor, Joaquim Casas i Carbó, que adverteix:

Potser respecte a alguna de les apreciacions secundaries hi hauria alguna cosa que dir, però com que en lo fonamental coincideix l'autor ab els fets y ab la manera com nosaltres els judiquèm, donèm íntegres aquets articles y sense cap comentari (Schädel 1905: 5e).

28 La carta de Saroïhandy es pot llegir dins Julià-Muné (2000: 88). 
Adrià Martí-Badia. Els postulats de la filologia romànica internacional sobre l'origen, la identitat i el nom de la llengua catalana (1806-1906)

Rafanell (2006: 314-315), d'una banda, suggereix la possibilitat que aquesta nota puga ser una crítica encoberta de Schädel al Meyer-Lübke de l'Einführung in die romanische Sprach-wissenschaft $(1901)^{29} \mathrm{el}$ qual -com hem vist adés- es mantenia en la posició occitanista; i, de l'altra, que la redacció del setmanari es va veure esperonada a afegir la nota a peu de pàgina. De fet, la segona part del treball de Schädel no va arribar a publicar-se.

\title{
4. Els romanistes que no s'hi van posicionar
}

També hi havia qui constatava la divisió d'opinions entre els qui consideraven que el català era un dialecte de l'occità i els qui el consideraven una llengua independent. És el cas del lingüista francés Abel Hovelacque, que l'any 1876 publica La linguistique i comenta aquesta divisió d'opinions quan parla del provençal,

\begin{abstract}
que era i encara és, de fet, només un dels dialectes de la llengua d'oc: hem de situar al seu costat el llemosí, l'alvernés, el dialecte d'una part del Delfinat [= provençal-alpí] i el gascó. Sovint s'ha qüestionat si el català, que hui ocupa Catalunya, València, les Illes Balears i el territori anteriorment aragonés, ha d'estar entre els dialectes del provençal o constituir en si mateix una veritable llengua neollatina. La qüestió no es resol, però no podem culpar absolutament als autors que persisteixen en no separar el català dels dialectes provençals i, per tant, el lliguen a la llengua d'oc (1876: 267).
\end{abstract}

Unes pàgines més endavant, quan Hovelacque parla dels límits del castellà, afirma que

a l'est s'estén només com a llengua literària a Catalunya i València, on la llengua popular és el català, del qual hem parlat en tractar el provençal. L'espanyol també va conquerir Aragó, on abans també es parlava el dialecte català (1876: 270-271).

També trobem el romanista estatunidenc Charles Hall Grandgent, que l'any 1905 publica An outline of the phonology and morphology of Old Provençal, en la qual afirma que

el franco-provençal i el català (...) estan estretament relacionats amb el provençal i no sempre són fàcils de separar. El català, de fet, sovint es considera un dialecte provençal, però és prou diferent per a ésser estudiat per separat (1905: 2).

Com afirma Calaforra (1998: 32), Grandgent es mostra partidari d'una certa autonomia per al català, però és bastant poc taxatiu.

29 També podria ser una crítica a la Grammatik de Meyer-Lübke (1890-1901), on defensa la mateixa posició que a l'Einfübrung (1901) pel que fa al català.

SCRIPTA, Revista internacional de literatura i cultura medieval i moderna, núm. 13 / juny 2019 / pp. 60 - 80 
Adrià Martí-Badia. Els postulats de la filologia romànica internacional sobre l'origen, la identitat i el nom de la llengua catalana (1806-1906)

I, el tercer i últim dels qui no s'afegeixen a cap de les dues teories és el romanista austríac Johann Hadwiger, ${ }^{30}$ que l'any 1905 va publicar un article sobre els límits de la llengua catalana al País Valencià fent una descripció bastant exacta. Un treball en què, evidentment, Hadwiger (1905) no qüestiona la pertinença del «valencianische» al conjunt del «katalanische», noms que empra al llarg de l'article.

No obstant això, una cosa era l'estudi -on hem vist que hi havia romanistes partidaris de la teoria occitanista i els qui defensaven la teoria contrària- i una altra ben diferent era la distància lingüística real dels catalanoparlants respecte dels occitanoparlants. La separació del català amb els diferents parlars occitans era tan gran que la intercomprensió entre els seus parlants esdevenia una missió impossible. Així ho descriu el filòleg francés Gaston Paris en una trobada felibrenca amb occitans i catalans l'any 1873, que per a entendre's havien de comunicar-se en francés (Rafanell 2006: 99).

\section{E1 nom de la llengua catalana}

Un altre era el debat onomàstic, sobre el qual la romanística internacional fou unànime en l'ús dels noms «català» $\mathrm{i}$ «llengua catalana» per a referir-se al conjunt de la llengua catalana. En aquest article hem observat com tots els romanistes empraven aquestes precises denominacions, tant aquells que consideraven el català una llengua independent com els que la consideraven un dialecte de l'occità. I només tres d'aquests romanistes van explicar aquesta denominació; una escassesa de participació que es deu -ben probablement- al fet que aquest nom no donava lloc a dubtes: està molt documentat històricament, la gran majoria dels parlants l'empren per a referir-se a la llengua que parlen, i coincideix amb el nom del territori on es parla. ${ }^{31} \mathrm{~A}$ més, dos dels tres romanistes són espanyols, fet que denota que el poc debat que hi havia es limitava als territoris al sud dels Pirineus.

El primer que analitza aquesta qüestió és l'esmentat Menéndez Pelayo, concretament en el discurs d'obertura que va llegir en català als Jocs Florals de Barcelona de 1888 davant de la reina regent. Menéndez Pelayo va censurar les denominacions errònies amb les paraules següents:

Eixa llengua, rebrot generós del tronch llatí, jeya, no fa mitj segle, en trista y vergonyosa postració. Fins son nom propi y genuí se li negava, ni ¿qui li havía de coneixer sots la disfressa d'aquelles peregrines denominacions de llemosina y provensal ab que solian designarla'ls pochs

30 De Johann Hadwiger sabem, gràcies a Corbera (2006a: 82-83), que el 1903 va anar a Mallorca, després d’haver estat per la Península estudiant els dialectes romànics i es va trobar amb Antoni M. Alcover. Després de l'estada a Mallorca va continuar la recerca lingǘstica pel País Valencià i el Pirineu català, viatge del qual sembla que són fruit les dues úniques obres dedicades al català que en coneixem $(1905,1907)$. A més, va mantenir correspondència amb Alcover entre els anys 1903 i 1914.

$31 \mathrm{O}$ almenys coincideix amb Catalunya, el territori que aleshores tenia $-\mathrm{i}$ ara hi continua tenint- el major nombre de parlants.

SCRIPTA, Revista internacional de literatura i cultura medieval i moderna, núm. 13 / juny 2019 / pp. 60 - 80 
Adrià Martí-Badia. Els postulats de la filologia romànica internacional sobre l'origen, la identitat i el nom de la llengua catalana (1806-1906)

erudits que's dignavan recordarse d'ella, encara que fos per donarla per morta y rellegarla desdenyosament á algun museu d'antigalles? (1942: 111).

Ara bé, cal tindre en compte el context en què es va produir el discurs, a la Barcelona de 1888, on el llemosinisme onomàstic feia anys que havia estat liquidat. Un any després, Menéndez Pelayo arremetia contra aquells que encara empraven la inexacta denominació amb les paraules següents: «iY qué completa debía ser la ilusión cuando el trovador cantaba trovas lemosinas, como todavía llaman algunos majaderos de Castilla y de fuera de ella a los versos compuestos en lengua catalana!» (1942: 122-123).

Un altre erudit que analitza aquesta qüestió és el filòleg francés Paul Meyer en un article de 1889 publicat dins Annales du Midi sobre els diferents noms que l'esmentada «llengua romana» havia tingut al llarg de la història. Quan analitza l'origen del nom «llemosí» afirma que fou l'escriptor català del segle XIII Ramon Vidal de Besalú qui va ampliar deliberadament el significat d'aquesta paraula, sense explicar els motius de la seua elecció, però segurament degut a la gran reputació dels trobadors llemosins; una elecció que va tindre molt d'èxit i gran difusió a Catalunya (1889: 10). I, tot seguit, Meyer rebla el clau:

I quan els catalans van començar a compondre en llur llengua, seguint els usos poètics $i$ àdhuc gramaticals dels poetes provençals o, com ells deien -llemosins- donaren a l'idioma, voluntàriament acostat al provençal de què se servien, el nom de lenga lemosina, que es manté en ús i ha donat lloc a moltes confusions i concepcions inexactes (1889: 10).

I el tercer i últim romanista que parla sobre el nom de la llengua és el filòleg espanyol Ramón Menéndez Pidal en l'article de 1902 que hem comentat adés.

\section{Conclusions}

Comptat $\mathrm{i}$ debatut, els romanistes estrangers d'aquest període temporal mantenen posicions diferents quant a la consideració del català com a llengua independent o dialecte de l'occità. Així, des dels inicis de la romanística, hi van haver actituds variades respecte a aquesta segona qüestió. D'una banda, no fou considerada en el nivell màxim de llengua pels romanistes Johann Christoph Adelung i Johann Severin Vater (1806-1817), François Raynouard (1816-1821), August Wilhelm von Schlegel (1818), Lorenz Diefenbach (1831), George Cornewall Lewis (1835), Friedrich C. Diez (1836-1844, 1856-1860), August Fuchs (1840), J. F. Schnakenburg (1840), Arthur Bruce-Whyte (1841), August Schleicher (1850), Alfred Morel-Fatio (1888), Wilhelm Meyer-Lübke (1890-1901, 1901), Antonio Restòri (1891), Vincenzo Crescini (1892 i 1905), Gottardo Garòllo (1892-1895), Egidio Gorra (1894), Adolf Zauner (1900) i Oskar Schultz-Gora (1906), que es mantenien en la teoria «tradicional» $\mathrm{O}$ «occitanista», segons la qual el català era un dels dialectes de la llengua occitana, llavors coneguda generalment amb el nom de «provençal». En canvi, van reconéixer el català com

SCRIPTA, Revista internacional de literatura i cultura medieval i moderna, núm. 13 / juny 2019 / pp. 60 - 80 ISSN: 2340-4841 · doi:10.7203/SCRIPTA.13.15436 
Adrià Martí-Badia. Els postulats de la filologia romànica internacional sobre l'origen, la identitat i el nom de la llengua catalana (1806-1906)

a llengua independent els romanistes Friedrich C. Diez (1827, 1870, 1876-1877, 1882), Gustav Körting (1884-1888), Fritz Neumann (1886), Gustav Gröber (1888-1901), Marcelino Menéndez Pelayo (1889), Otto Denk (1893), Ramón Menéndez Pidal (1902), Jean Joseph Saroihandy (1904) i Bernhard Schädel (1905). A més, entre aquests també hem observat que Diez, Körting, Gorra i Saroihandy van vacil lar en aquest assumpte.

Altrament, uns pocs romanistes no van posicionar-se ni amb una teoria ni amb l'altra, per tres motius: a) perquè no era l'objecte del seu estudi, b) perquè les seues afirmacions no són suficientment nítides com per a agrupar aquests autors en cap de les dues posicions, i c) perquè simplement constaten que hi ha dues opcions sense prendre partit per cap d'elles. El primer motiu és el cas de Hadwiger, el segon és el de Grandgent i també de Hadwiger, i el tercer és el de Hovelacque.

En definitiva, els romanistes del període comprés entre 1806 i 1906 van adoptar diferents posicions respecte al català, però les més influents van ser dues: una, la que el considerava un dialecte occità; l'altra, la que hi veia una llengua romànica independent. Ambdues opinions tenien un pes semblant, però l'«occitanista» - com observa Calaforra (1998: 33) - va veure's catapultada a l'«oficialitat»a partir de la primerenca producció teòrica de Whilhelm Meyer-Lübke (la Grammatik i l'Einfübrung).

De fet, al Primer Congrés Internacional de la Llengua Catalana celebrat el 1906 a Barcelona hi van assistir romanistes estrangers com els francesos Jean-Joseph Saroïhandy i Louis Barrau-Dihigo, els alemanys Bernhard Schädel i Eberarth Vogel Müller, els occitans Raymond Foulché-Delbosc i Jean-Auguste Brutails, l'italià Pier Enea Guarnerio i l'espanyol Adolfo Bonilla San Martín. ${ }^{32}$

Tot amb tot, les dues dècades següents es mantindria la discussió sobre aquesta qüestió amb romanistes com els esmentats Meyer-Lübke i Schultz-Gora, l'occità Joseph Anglade, el francés Édouard Bourciez, l'esmentat Bernhard Schädel, els també alemanys Fritz Krüger i Karl Salow ambdós deixebles de Schädel-, i el suís Walther von Wartburg. Encara caldria esperar dues dècades de vacil lacions entre ambdues teories fins a l'any 1925, quan el mateix Meyer-Lübke -aleshores líder de la romanística internacional- va publicar Das Katalanische, ${ }^{33}$ l'obra que el conjunt de la romanística i de la catalanística consideren l'estudi que va cloure aquesta discussió filològica.

32 Vegeu Corbera (2006b) per a la participació estrangera en el Primer Congrés Internacional de la Llengua Catalana. 33 Vegeu Calaforra (1998) per a la traducció al català i per a l'estudi d'aquesta obra. 
Adrià Martí-Badia. Els postulats de la filologia romànica internacional sobre l'origen, la identitat i el nom de la llengua catalana (1806-1906)

\section{Bibliografia}

Adelung, J. C. / Vater, J. S. (1806-1817) Mithridates oder allgemeine Sprachenkunde, Berlin, Vossische buchhandlung, 4 vol.

Badia i Margarit, A. M. (1981 [1a ed. 1951]) Gramàtica històrica catalana, València, Tres i Quatre.

—_. (1989) «Presència internacional de la llengua catalana», dins Ferrando, A. (ed.), Segon Congrés Internacional de la llengua catalana, vol. vIII, València/Barcelona, IFV/PAM, pp. 3-18.

Baldinger, K. (1972 [1a ed. 1958]) La formación de los dominios lingüísticos de la penñinsula ibérica, Madrid, Gredos.

Bastero, A. de (1724) La Crusca Provenzale, Roma, Antonio dei Rossi.

Bayà, M. R. / Pascual, N. (1992) «La identitat del català com a llengua romànica: opinions dels segles XVIII i XIX», Anuari de Filologia. Secció C. Llengua i Literatura Catalanes, 3, pp. 21-45.

Bruce-Whyte, A. (1841) Histoire des langues romanes et de leur littérature, París, Treuttel et Würtz, 3 vol.

Calaforra, G. (1998) Whilhelm Meyer-Lübke $i$ Das Katalanische. Introducció i traducció, Barcelona, IEC.

Corbera, J. (2006a) (ed.) Crònica de l'obra del Diccionari, Palma, Moll.

—. (2006b) «L'aportació dels participants estrangers al Primer Congrés Internacional de la Llengua Catalana», Mirall, 175, pp. 11-19.

Crescini, V. (1892) Manualetto provenzale per uso degli alunni delle facoltà di lettere, Verona/Pàdua, Fratelli Drucker.

- (1905) Manualetto provenzale per uso degli alunni delle facoltà di lettere, Verona/Pàdua, Fratelli Drucker, $2 \mathrm{a}$ ed.

Denk, O. (1893) Einfübrung in die Geschichte der altkatalanischen Litteratur von deren Anfängen bis zum 18. Jahrbundert, Munic, Münchner Handelsdruckerei \& Verlangsanstalt M. Poessl.

Diefenbach, L. (1831) Über die jetəigen romanischen Schriftsprachen, Leipzig, J. Ricker.

Diez, F. C. (1836-1844) Grammatik der romanischen Sprachen, Bonn, Eduard Weber, 3 vol.

- (1856-1860) Grammatik der romanischen Sprachen, Bonn, Eduard Weber, 3 vol., 2a ed.

- (1870) Grammatike der romanischen Sprachen, Bonn, Eduard Weber, 3 vol., 3 a ed.

- (1876-1877) Grammatik der romanischen Sprachen, Bonn, Eduard Weber, 3 vol., 4a ed.

- (1882) Grammatik der romanischen Sprachen, Bonn, Eduard Weber, 3 vol., 5a ed.

Fuchs, A. (1840) Über die sogenannten unregelmässigen Zeitwörter in der romanischen Sprachen, Berlin, Verlag Von A. Asher \& Comp.

—. (1849) Die romanischen Sprachen in ibrem Verbältnisse zum Lateinischen, Halle, Druck und Verlag Von H. W. Schmidt.

Garòllo, G. (1892-1895) Piccola Enciclopedia Hoepli, Milà, Hoepli, 2 vol. 
Adrià Martí-Badia. Els postulats de la filologia romànica internacional sobre l'origen, la identitat i el nom de la llengua catalana (1806-1906)

Gorra, E. (1894) Lingue neolatine, Milà, Ulrico Hoepli.

Grandgent, C. H. (1905) An outline of the phonology and morphology of Old Provencal, Boston, D. C. Heath \& Co.

Gröber, G. (1888-1901) Grundriß der romanischen Philologie, Estrasburg, K. J. Trubner, 4 vol.

Hadwiger, J. (1905) «Sprachgrenzen und Grenzmundarten des Valencianischen», Zeitschrift für romanische Pbilologie, 29, pp. 712-731.

—. (1907) «Das haupttonige a im Mallorkinischen», Romanische Forschungen, 20, pp. 713-740.

Hovelacque, A. (1876) La linguistique, París, C. Reinwald et Cie.

Julià-Muné, J. (2000) L'inici de la lingüística catalana. Bernhard Schädel, Mn. Antoni M. Alcover i l'Institut d'Estudis Catalans. Una aproximació epistolar, 1904-1925, Barcelona, Curial/PAM.

Kuhn, A. (1937) «Wilhelm Meyer-Lübke», Zeitschrift für Romanische Philologie, 57, pp. 778-784.

Körting, G. (1884-1888) Ensyklopädie und Methodologie der romanischen Philologie, Heilbronn, Gebr. Henninger, 3 vol.

—. (1896) Handbuch der romanischen Philologie, Leipzig, O. R. Reisland.

Lewis, G. C. (1835) An essay on the origin and formation of the Romance languages, Oxford, D. A. Talboys.

Martí-Badia, A. (2018) Les ideologies lingüistiques dels valencians de la segona meitat del vuit-cents i principis del nou-cents (1854-1906), Tesi doctoral inèdita, Universitat de València.

Massot i Muntaner, J. (2018) Els mallorquins i la llengua catalana. Segles XIII-XXI, Barcelona, PAM.

Menéndez Pelayo, M. (1889) «Prólogo», dins Gayter del Llobregat, Lo, Poesías de Joaquim Rubió y Ors. Edició políglota, vol. II, Barcelona, Jaume Jepús y Roviralta, pp. VII-XXIII.

—_. (1942) Estudios y discursos de crítica histórica y literaria. Siglo XIX, Madrid, CSIC.

Menéndez Pidal, R. (1902) «El catalán y los catalanistas. Cataluña bilingüe», El Imparcial 15-12-1902, p. 1 abc.

Meyer, P. (1889) «La langue romane du midi de la France et ses différents noms», Annales du Midi, 1, pp. 1-15.

Meyer-Lübke, W. (1890-1901) Grammatik der romanischen Sprachen, Leipzig, Reisland, 4 vol.

—. (1901) Einfübrung in das Studium der romanischen Sprachwissenschaft, Heidelberg, Carl Winter's Universitätsbuchhandlung.

—. (1925) Das Katalanische, Heidelberg, Carl Winter's Universitätsbuchhandlung.

Moll, F. de B. (2006 [1a ed. 1952]) Gramàtica històrica catalana, València, PUV.

Morel-Fatio, A. (1888) «Das Catalanische», dins Gröber, G., Grundriß der romanischen Philologie, vol. I, Estrasburg, K. J. Trubner, pp. 669-688.

Müller, B. (1983) «Das Katalanische in der Entwicklung des Sprachenkatalogs der romanischen

SCRIPTA, Revista internacional de literatura i cultura medieval i moderna, núm. 13 / juny 2019 / pp. 60 - 80 
Adrià Martí-Badia. Els postulats de la filologia romànica internacional sobre l'origen, la identitat i el nom de la llengua catalana (1806-1906)

Sprachwissenschaft», dins Estudis de llengua i literatura catalanes oferts a R. Aramon i Serra, vol. III (Estudis Universitaris Catalans, XXV), Barcelona, Curial, pp. 397-411.

Neumann, F. (1886) Die Romanische Pbilologie, ein Grundriß, Leipzig, Fueis.

Rafanell, A. (2006) La il lusió occitana, Barcelona, Quaderns Crema, 2 vol.

Raynouard, F. (1816-1821) Choix des poésies originales des Trobadours, París, Firmin Didot, 6 vol.

- (1836) Influence de la langue romane rustique sur les langues de l'Europe latine, París, Crapelet.

- (1836-1844) Lexique roman ou dictionnaire de la langue des troubadours, comparée avec les autres langues de l'Europe latine, París, Silvestre, 6 vol.

Restòri, A. (1891) Letteratura Provenzale, Milà, Ulrico Hoepli.

Sanchis Guarner, M. (1980) Aproximació a la bistòria de la llengua catalana, Barcelona, Salvat.

Saroïhandy, J.-J. (1904) «Das Catalanische», dins Gröber, G. Grundriß der romanischen Philologie, vol. I, Estrasburg, K. J. Trubner, 2a ed., pp. 841-877.

Schädel, B. (1905) «La llengua catalana en el passat y en el present», El Poble Català, 22, pp. 2ef-3a.

Schlegel, A. W. von (1818) Observations sur la langue et la littérature provençales, París, J. Smith.

Schleicher, A. (1850) Die sprachen Europas in systematischer Uebersicht, Bonn, H. B. König.

Schnakenburg, J. F. (1840) Tableau synoptique et comparatif des idiomes populaires on patois de la France, Berlín, Albert Foerstner.

Schultz-Gora, O. (1906) Alprovenzalisches Elementarbuch, Heidelberg, Carl Winter’s Universitätsbuchhandlung.

Seifert, E. (1936) «Das Katalanische in den Werken von Friedrich Diez», dins Homenatge a Antoni Rubió i Lluch. Miscel lània d'estudis literaris, històrics i lingüistics, vol. I, Barcelona, pp. 193-199.

Solà, J. (1985) «L'origen de la llengua al segle XIX català», dins Homenatge a Antoni Comas, Barcelona, Universitat de Barcelona, pp. 457-478.

Trueta, J. (1988 [1a ed. 1946]) L'esperit de Catalunya, Barcelona, Selecta.

Vàrvaro, A. (1988 [1a ed. 1968]) Historia, problemas y métodos de la lingüística románica, Barcelona, Sirmio.

Wittlin, C. (1992) «Algunes reflexions en ocasió del centenari de la Geschichte der altcatalanischen litteratur d'Otto Denk», Revista de Catalunya, 69, pp. 115-129.

Zauner, A. (1900) Romanische Sprachwissenschaft, Leipzig, G. J. Göschen. . (1905) Romanische Sprachwissenschaft, Leipzig, G. J. Göschen, 2 vol., 2 a ed. 